\title{
FOUR NEW TENTHREDO LINNAEUS, 1758 SPECIES FROM SIKKIM (HYMENOPTERA, TENTHREDINIDAE)
}

\author{
A. Haris*
}

\begin{abstract}
Four new Tenthredo Linnaeus, 1758 species are described from Sikkim, India: $T$. nigroypsilon sp. n. , T. memoriaescalerai sp. n., T. allantosikkimensis sp. n. and Tenthredo minutosimplicis sp. n. and compared to T. maruana Malaise, 1945, T. variicolor Malaise, 1945, T. maculipennis Malaise, 1945, T. coloripleuris Malaise, 1945 and T. changbuensis Haris, 2000.
\end{abstract}

Key words: Hymenoptera, Tenthredinidae, Tenthredo, new species, Sikkim, India.

\section{RESUMEN}

\section{Cuatro nuevas especies de Tenthredo Linnaeus, 1758 de Sikkim} (Hymenoptera, Tenthredinidae)

Se describen cuatro nuevas especies de Tenthredo Linnaeus, 1758 procedentes de Sikkim, India: T. nigroypsilon sp. n., T. memoriaescalerai sp. n., T. allantosikkimensis sp. n. y Tenthredo minutosimplicis sp. n. y se comparan con T. maruana Malaise, 1945, T. variicolor Malaise, 1945, T. maculipennis Malaise, 1945, T. coloripleuris Malaise, 1945 and T. changbuensis Haris, 2000.

Key words: Hymenoptera, Tenthredinidae, Tenthredo, nuevas especies, Sikkim, India.

\section{Introduction}

The extensive oriental Tenthredinidae collection of the Madrid Natural History Museum was established by Manuel Martinez de la Escalera (1867-1950) whose expedition at the end of the 19th century, to Sikkim, India, resulted in very rich sawfly material. A few specimens of his collection were studied by Konow and later by Malaise. The author studied this collection in February 2004 under the grant of the BIODIBERIA project, and found about 500 specimens still unidentified including 4 new species which are published in this paper.

\section{Material and Methods}

The genus Tenthredo Linnaeus, 1758 is the dominant sawfly genus of the family Tenthredinidae in the Oriental region. Most of the known species are described by Malaise (1945) whose expeditions to the South-Eastern Asiatic region resulted in an extremely rich material containing 108 new species and subspecies. He keyed and revised all oriental Tenthredo species described by earlier and contemporary authors. His work is still the only handbook for the identification of the oriental Tenthredininae genera and species. Since

* Petöfi str. 103, H-81242, Urhida, Hungary. 
the appearance of this work (Malaise, 1945), numerous Tenthredo species have been described from neighbouring India (Togashi, 1987; Muche, 1982, 1983; Vasu \& Saini, 1999; Saini \& Bharti 1996, 1997; Singh, 1985; Saini \& Vasu, 1999; Singh \& Saini, 1987a, b, 1988a, b, c, 1995; Saini et al., 1998; Singh et al., 1985) and China (Gangrou et al., 1992; Haris \& Roller, 1998; Nie \& Wei, 1998; Wei \& Nie, 1998a, b). Few additional species were reported from Bhutan (Muche, 1983; Haris, 2000), Nepal (Muche, 1986; Haris, 2000), Vietnam, Sikkim, Borneo (Shinohara, 1998) and Pakistan (Muche, 1982). All listed papers above were studied and used for the identification and comparison of the new species.

Genitalia were not dissected due to the historical value of the described specimens, (120 year-old collection!). They are very easily recognisable species (large and colourful) without any real close relatives. They only remotely resembles some others, which are discussed at the end of the descriptions. Saws-structure only very sporadically figured in the genus Tenthredo Linnaeus.

Only females were found, the males of these species are still unknown. Two of the four species are described from only one specimen. Despite the intensive research of the Indian sawfly fauna, no more specimens have been found since the time of Escalera.

\section{Results}

\section{Tenthredo nigroypsilon $\mathrm{sp} . \mathrm{n}$.}

(Figs. 1 and 2)

HoLotype: female, "Sikkim", Escalera collection. (No further data available)

PARATYPes: 3 females, "Sikkim", Escalera collection. (No further data available.) The holotype and paratypes are deposited in the Madrid Natural History Museum.

DESCRIPTION. Head yellow with a black Y-shaped spot only. This Y-shaped spot starts from the hind occipital carina towards the base of the supraantennal tubercles (Fig. 2). The lateral branches of the Y nearly reach the eyes. The steam of the Y involves a rounded yellow spot basally. Antennae yellow, black: apical halves of 6th segments and segments 7th-9th entirely. Thorax yellow. Lateral mesonotal lobes with 1-1 longitudinal black strips (Fig. 2). Metathorax mostly black except for the yellow mesoscutellum, mesoscutellar appendage and cenchri. Pronotum with black fore margin. Mesosternum surrounded by brown horizontal strip.
Legs yellow, only hind coxae with black strips. Wings yellowish hyaline. Stigma and costa yellow, venation brown. Abdomen dark yellow, tergites more or less covered with brownish shadow (Fig. 1). Ratios of the antennal segments: $19: 14: 48: 49$ $: 45: 38: 31: 27: 25$. OOL : POL : OCL: $9: 2: 6$. Vertex, temples and frontal area slightly shiny, unpunctured with superficial transverse sculpture. Mesonotal lobes very finely, very densely and uniformly punctured, slightly shiny. Mesoscutellum finely and densely punctured, hardly shiny. Mesopleuron nearly smooth and shiny, very densely, finely and superficially punctured. Abdominal tergites with very fine, superficial surface sculpture. Head strongly contracted behind the eyes with sharp occipital carina. Clypeus roundly emarginated. Depth of clypeal emargination : median length of clypeus: 3/11. Mesoscutellum blunt, subpiramidal. Mesopleuron bluntly elevated. Mesosternum without thorns. Subapical and apical teeth of claws either subequal in length or the apical teeth a little longer. Subapical teeth wider than apical. Length: $12.0-13.0 \mathrm{~mm}$, length of fore wing: $11.0-12.0 \mathrm{~mm}$.

ETYMOLOGY. The species name refers to the very characteristic black Y pattern on the head (adj.).

Comments. The new species is similar to Tenthredo maruana Malaise, 1945. Tenthredo maruana has the $3 \mathrm{rd}$ antennal segment distinctly longer than the 4th. Length of body is $14.5 \mathrm{~mm}$, apices of wings are infuscate and the black ocellar spot of the head is triangularly broadened below. The new species has subequal $3 \mathrm{rd}$ and 4 th antennal segments, smaller, 12.0-13.0 mm, wings are yellowish subhyaline, head without broadened ocellar spot but with Y-shaped pattern.

\section{Tenthredo memoriaescalerai $\mathrm{sp} . \mathrm{n}$.}

(Figs. 3 and 4)

HolotyPE: female, "Sikkim", Escalera collection. (No further data available).

PARATyPes: 2 females, "Sikkim", Escalera collection. (No further data available). The holotype and paratypes are deposited in the Madrid Natural History Museum.

DESCRIPTION. Head behind the eyes rusty brown. Vertex, inner sides of temples, frontal and supraantennal area covered with a rounded large black spot which never reaches the eyes. Labrum, clypeus, face below antennae, narrow inner orbits and narrow outer orbits light yellow (Fig. 4). Mandibles yellow with brownish apical halves. Antennae black, 7th- 

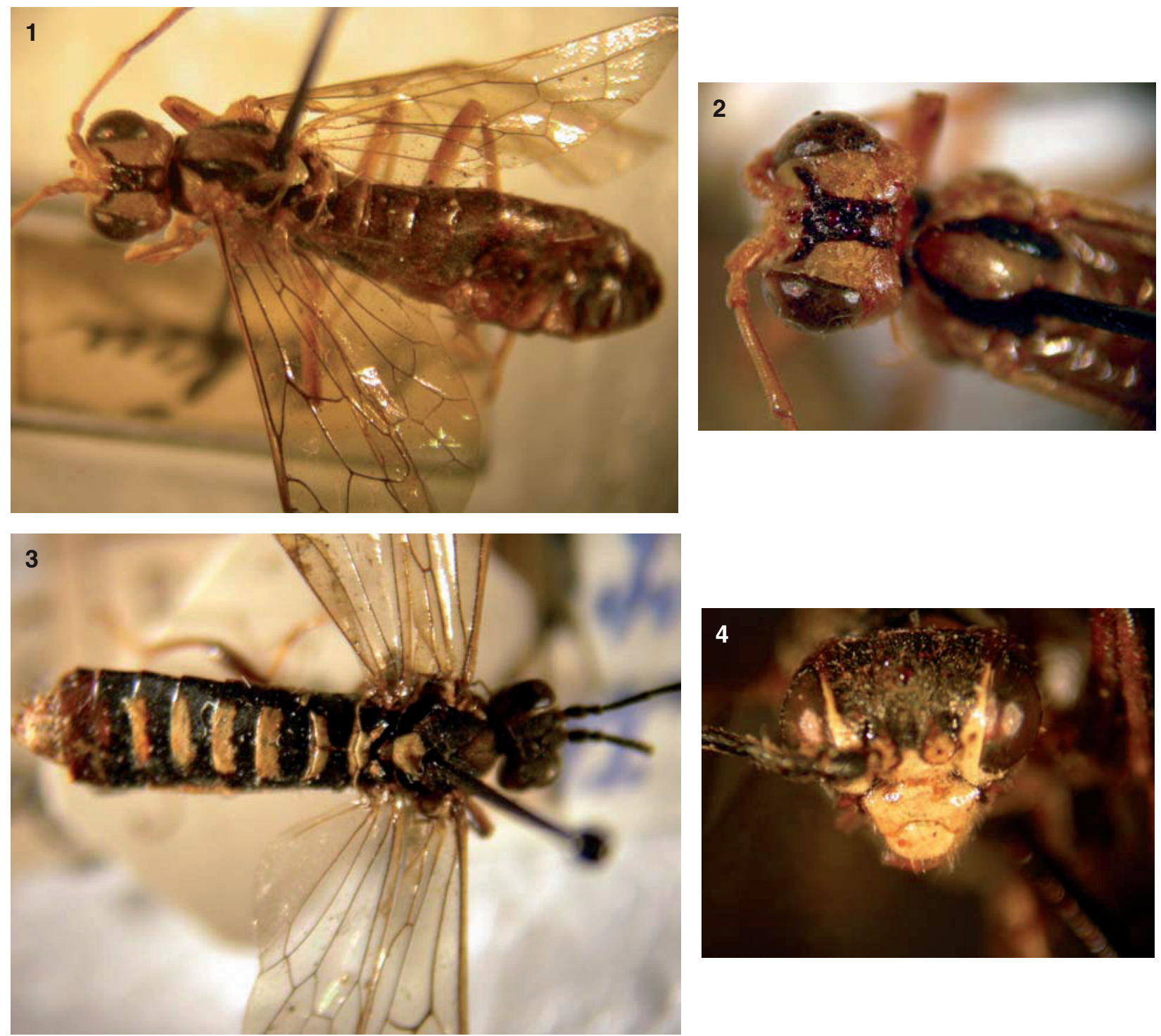

Figs. 1-4.- Tenthredo nigroypsilon sp. n.: 1) paratype, 2) head and thorax of holotype in dorsal view. Tenthredo memoriaescalerai sp. n.: 3) holotype, 4) head of paratype in frontal view.

Figs. 1-4.- Tenthredo nigroypsilon sp. n.: 1) paratipo, 2) cabeza y tórax del holotipo en vista dorsal. Tenthredo memoriaescalerai sp. n.: 3) holotipo, 4) cabeza de un paratipo en vista frontal.

9th and mostly the 6th antennal joints white, 9th joint brown below. Thorax brown. Lateral mesonotal lobes and metanotum black. Mesoscutellum, metascutellum, and cenchri yellowish white. Mesoscutellar appendage brownish yellow. Thorax laterally, ventrally and middle mesonotal lobes brown. Pronotum brown with black fore and yellowish white hind margin. Tegulae brownish yellow. Wings subhyaline, stigma and venation brown, costa yellow. Legs brown, apices of middle, apical halves of hind coxae, strips of fore and middle femora and apices of hind tibiae black. The black strips of middle femora do not extend the apical quarter in length. Abdominal tergites 1st-6th black. First tergite (propodeum) with yellowish white fore and hind margins, 2nd-5th only with yellowish white hind margins (Fig. 3). These hind margins may vary in width and may cover the hind margins of the 2nd-4th 
tergites only. Abdominal apex and abdominal sternites yellowish brown. Ovipositor brown. Vertex, temples and frontal area densely, moderately deeply, uniformly granulated, hardly shiny. Outer orbits with superficial dense punctures, shiny. Mesonotum, mesoscutellum and mesoscutellar appendage with uniform, dense and moderately deep punctures, subopaque. Mesopleuron with dense, superficial, uniform and small punctures, weekly shiny. Abdominal tergites with dense, superficial and coriaceous sculpture, shiny. Ratios of the antennal segments: $13: 9: 32: 26: 23 ; 19: 12: 11: 13$. OOL : POL : OCL: $9: 3: 7$. Length : width of the postocellar area $=2: 3$. Head slightly contracted behind the eyes. Mesos-cutellum blunt. Mesopleural projection blunt. Mesosternum without thorns. Clypeus widely and shallowly emarginated. Clypeal emargination about 0.25 times as deep as the clypeal median length. Subapical teeth longer than apical teeth. Length: $12.0 \mathrm{~mm}$, length of fore wing: $12.0 \mathrm{~mm}$.

ETYMOLOGY. This species is named in honour of Dr. Manuel Martínez de la Escalera (subs.).

Comments. The new species is related to Tenthredo variicolor Malaise, 1945. Tenthredo variicolor has mainly black abdominal tergites with bluish lustre and tergites 2nd-7th are mostly with lateral pale spots. The new species has abdominal tergites without any bluish lustre and tergites $1 \mathrm{st}-7$ th with wide yellowish hind margins, 1st tergite with additional fore margin. Abdominal apex is brown.

\section{Tenthredo allantosikkimensis $\mathrm{sp} . \mathrm{n}$.}

(Figs. 5 and 6)

Holotype: female, "Sikkim", Escalera collection. (No further data available). The holotype is deposited in the Madrid Natural History Museum.

DESCRIPTION. Head brown with large black dorsal spot covering the whole upper surface of the head starting from hind carina down to antennae, except for the narrow inner orbits which remain brown. Antennae black, flagellum dorsally and pedicel apically brown (Fig. 6). Prothorax brown but pronotum with black spots on its corners. Tegulae brown. Mesonotal lobes black only the middles lobes with brown hind margines. Postnotum black including scutelli, but apex of mesoscutellum and mesoscutellar appendage remain brown. Mesopleuron and mesosternum with large suffused black spots. Legs brown, all coxae, femora and tibiae with longitudinal black lines.
Wings hyaline, costa brown, stigma and venation brownish black. Very apices of fore wings slightly infuscate. 1st-4th abdominal segments (tergites and sternites as well) dirty white, 1st abdominal segment (propodeum) with narrow black fore and hind margins. 5th-9th segments and ovipositor black (Fig. 5). Ratios of the antennal segments: $14: 14$ : 32:23:19:15:13:12:12. OOL : POL : OCL: $18: 3: 13$. Vertex, temples and frontal area densely, uniformly and strongly granulated, matt. Mesonotum, mesoscutellum and mesoscutellar appendage finely granulated, matt. Supraclypeal area densely, finely, uniformly punctured, shiny. Mesopleuron very finely, superficially granulated, moderately shiny. Abdominal tergites 1st-9th with fine, dense and superficial sculpture, moderately shiny. Head with sharp hind carina, postscutellar furrows hardly visible. Clypeus very deeply, roundly emarginated. Depth of clypeal emargination : median length of clypeus: $2 / 3$. Antennae shorter than head and thorax combined (Fig. 6). Mesoscutellum blunt. Mesopleural elevation strong but not acute. Mesosternum without thorns. Apical teeth of claws little longer than subapical teeth. Length: $11.5 \mathrm{~mm}$, length of fore wing: $12.0 \mathrm{~mm}$.

Etymology. Allanto: this species reminds for an Allantus species; sikkimensis: refers to the place where the type is captured (adj.).

Comments. The new species is related to Tenthredo maculipennis Malaise, 1945. Tenthredo maculipennis has sharp postocellar furrows, body with bluish shine, 5 basal abdominal tergites white with large black spots and head polished, inpunctate. The new species has hardly visible postocellar furrows, body without bluish shine, 4 basal abdominal segment white without black spots and head very densely punctured, matt. This species has intermediary position between the subgenus Tenthredo Linnaeus, 1758 which is characterised by short and gradually widened antennae and the subgenus Tenthredella Rohwer, 1910, which is characterised by long filiform antennae.

\section{Tenthredo minutosimplicis $\mathrm{sp} . \mathrm{n}$.}

(Fig. 7)

HolotyPe: female, “Sikkim", Escalera collection. The holotype is deposited in the Madrid Natural History Museum.

DESCRIPTION. Head brown with large black dorsal spot. This black spot nearly covers the entire dorsal surface, only the inner orbits and supraan- 

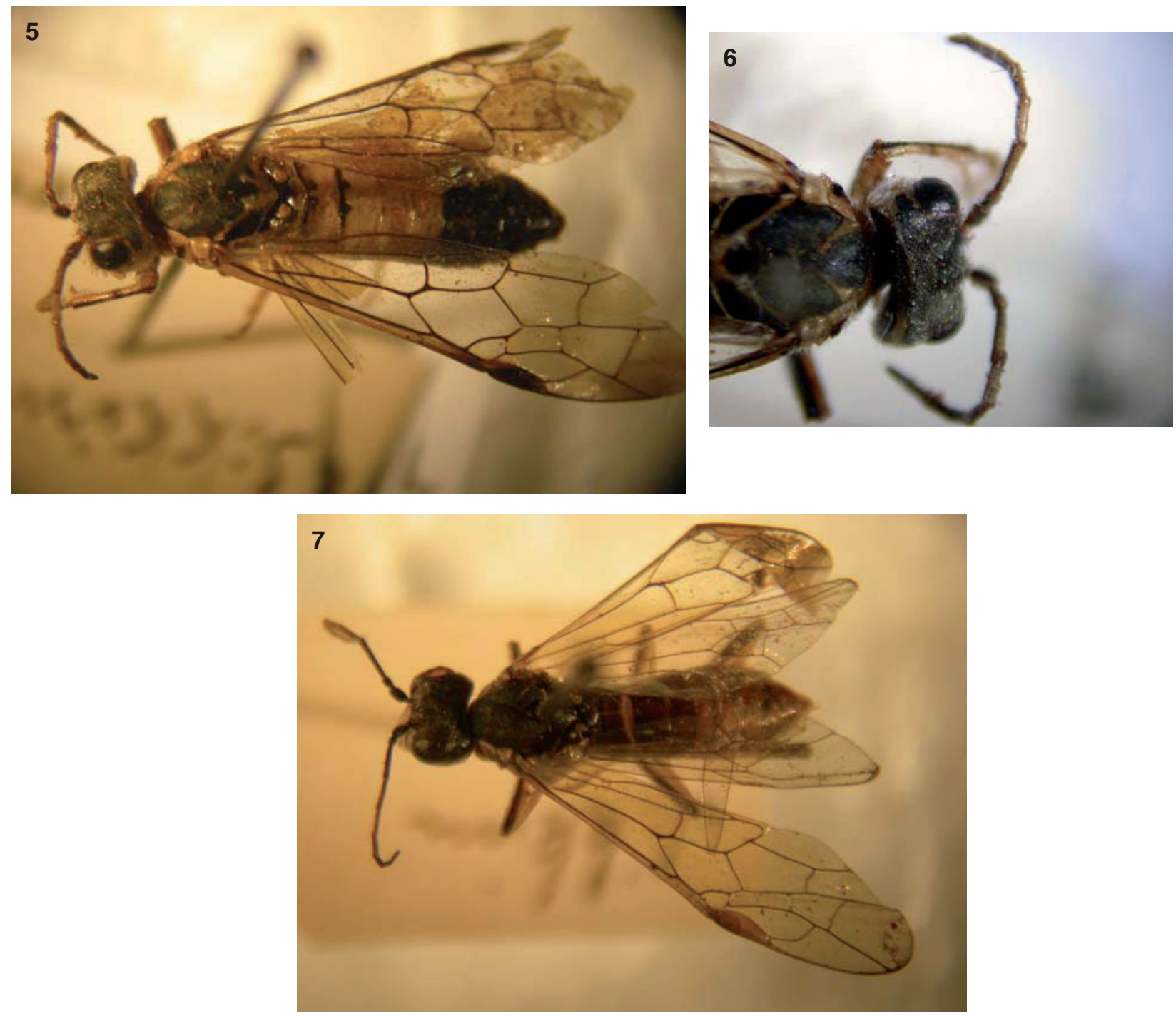

Figs. 5-7.- Tenthredo allantosikkimensis sp. n.: 5) holotype, 6) Head and thorax of holotype in dorsal view. Tenthredo minutosimplicis sp. n.: 7) holotype.

Figs. 5-7.- Tenthredo allantosikkimensis sp. n.: 5) holotipo, 6) Cabeza y tórax del holotipo en vista dorsal. Tenthredo minutosimplicis $\mathrm{sp}$. n.: 7) holotipo.

tennal tubercles remain black. Antennae black, whitish brown: apical 2/3 of 4th and 5th-9th segments entirely. Prothorax ivory white with narrow black fore margin and small lateral black spots. Tegulae ivory white. Mesonotum and postnotum entirely black. Lateral and ventral sides of the thorax entirely brownish white with suffused black strip on mesopleuron, with sharp black limit between mesepimeron and katepimeron and with black upper margin on the mesopleuron which separates it from the parapterum. Legs brownish white, all femora and basal 1/3 of all tibiae with longitudinal black lines. Wings hyaline, venation blackish brown, stigma and costa yellow. Abdominal tergites brown, 1st and 2nd tergites black the others coloured with suffused blackish shade more or less covering the brown ground-colour (Fig. 7). Abdominal sternites and ovipositor brownish white. Ratios of the antennal segments: $13: 9: 28: 19: 17: 13: 11$ : $9: 10$. OOL : POL : OCL: $13: 3: 10$. Vertex, tem- 
ples and frontal area, including inner orbits, densely and uniformly granulated without interspaces, hardly shiny. Mesonotum and mesoscutellum very densely and very finely granulated, nearly matt, hardly shiny. Metascutellum smooth and shiny. Mesopleuron with very fine, superficial, hardly visible granulation, bluntly shiny. Abdominal tergites including the 1st with fine transverse sculpture. Head contracted behind the eyes with sharp hind carina. Clypeus roundly and slightly emarginated. Depth of clypeal emargination : median length of clypeus: $2: 9$. Antenna slender, about as long as head and thorax combined. Mesopleuron clearly but bluntly elevated. Mesoscutellum subpiramidal, bluntly elevated. Mesosternum without thorns. Apical and subapical teeth of claws subequal. Length: $8.0 \mathrm{~mm}$. Length of fore wing: $9.0 \mathrm{~mm}$.

ETyMOLOGY. The species name refers to the small size of the sawfly and it's very simple appareance without conspicuous coloration (adj.)

COMMENTS. The new species is closely related to Tenthredo coloripleuris Malaise, 1945 and Tenthredo changbuensis Haris, 2000.

Tenthredo coloripleuris has blackish stigma. Tegulae black with pale margines. Legs are reddish and coxae are striped with black. The new species has yellow stigma, white tegulae, brownish white legs and femora are striped with black. Tenthredo changbuensis has white orbits, black prothorax with white hind pronotal margin, 1st, 5th and 6th tergites are black, sternites and ovipositor are brown. The new species has brown orbits, white prothorax with small black spots, 1st and 2nd tergites are black; sternites and ovipositor are brownish white.

\section{ACKNOWLEDGEMENTS}

I wish to express my grateful thanks to Dr. Carolina Martín and Dr. Jose Luis Nieves Aldrey for their support of my work.

\section{References}

Xiao, G., Huang, X., Zhou, S., Wu, J. \& Zhang, P., 1992. Economic Sawfly Fauna of China. Tianze Eldonejo. 221 pp.

HARIS, A., 2000. New Oriental Sawflies (Hymenoptera: Tenthredinidae). Somogyi Muzeumok Közleményei, 14: 297-305.

Haris, A. \& Roller, L., 1998. Three new Tenthredo species from Yunan (Hymenoptera: Tenthredinidae). Folia entomologica hungarica, 59: 135-140.
Malaise, R., 1945. Tenthredinoidea of South-Eastern Asia with a general zoogeographical review. Berlingska Boktryckeriet. Lund. 288 pp.

Muche, H. W., 1982. Beitrag zur Blattwespenfauna von Indien und Pakistan, mit Beschreibung einer neuen Art sowie Unterart (Hymenoptera, Symphyta, Tenthredinidae). Reichenbachia, Staatliches Museum für Tierkunde Dresden, 20(15): 113-117.

Muche, H. W., 1983. Die von Herrn Dr. W. Wittner in Indien und Bhutan gesammelten Blattwespen, mit Beschreibung von sechs neuen Arten der Tenthredinidae (Hymenoptera: Symphyta). Reichenbachia, Staatliches Museum für Tierkunde Dresden, 21(29): 167-180.

Muche, H. W., 1986. Beitrag zur Symphytenfauna von Nepal. Reichenbachia, Staatliches Museum für Tierkunde Dresden, 24(9): 79-90.

NIE, H. \& WeI, M., 1998. Fourteen new species of Tenthredo from Funiushan (Hymenoptera: Tenthredinidae). Insect Fauna of Henan Province, 2: 176-187.

Saini, M. S. \& Bharti, H., 1996. Addition of Five New Species to the Indian Tenthredo Linnaeus (Tenthredinidae, Hymenotera) from North-West India. Annals of Entomology, 14(2): 61-67.

SAINI, M. S. \& Bharti, H., 1997. New Indian Tenthredo species (Hymenoptera: Tenthredinidae) from the North-eastern Himalayas. Folia entomologica hungarica, 58: 173-181.

SAINI, M. S., SinGH, B. \& VASU, V. 1998. Two new species of Tenthredo Linnaeus (Hymenoptera, Symphyta, Tenthredinidae: Tenthredininae) from India. Journal of entomological Research, 22(1): 55-60.

SAINI, M. S. \& VASU, V., 1999. New species of Tenthredo Linnaeus from India (Hymenoptera: Tenthredinidae). Polskie Pismo entomologiczne, 68: 133-142.

ShinoharA, A., 1998. Southeast Asian Wasp-like Sawflies of the Tenthredo scrobiculata Group (Hymenoptera, Tenthredinidae). Bulletin of the national Science Museum, Tokyo, 24(2): 107-140.

SingH, B., 1985. Sawflies of Genus Tenthredo Linnaeus (Hymenoptera: Tenthredinidae) - Two New Species from Himachal Pradesh, India. Annals of Biology, 1(2): 179-183.

Singh, B, Singh, T. \& Dhillon, S. S., 1985. Two new species of genus Tenthredo Linnaeus (Hymenoptera: Tenthredinidae) from Northwest Himalaya, India. Uttar Pradesh Journal of Zoology, 5(1): 37-41.

Singh, D. \& SAINI, M. S., 1987a. Five new species of Tenthredo Linnaeus from Uttarkhand area (India) (Hymenoptera, Tenthredinidae). Deutsche entomologische Zeitschrift, 34(4-5): 397-405.

SingH, D. \& SAINI, M. S., 1987b. Six new species of Tenthredo Linnaeus from Northwestern India 
(Hymenoptera, Symphyta, Tenthredinidae). Reichenbachia, Staatliches Museum für Tierkunde Dresden, 24(29): 189-198.

Singh, D. \& SAINI, M. S., 1988a. Five new species of Tenthredo Linnaeus from the Eastern Himalaya (Hymenoptera, Tenthredinidae). Deutsche entomologische Zeitschrift, 35(4-5): 387-394.

Singh, D. \& SAINI, M. S., 1988b. Six new species of Tenthredo Linnaeus (Hymenoptera: Tenthredinidae) from Northern India. Journal of Bombay Natural History Society, 85(2): 366-375.

SingH, D. \& SAINI, M. S., 1988c. Six new species of Tenthredo Linnaeus from the Western Himalayas (Insecta, Hymenoptera, Symphyta, Tenthredinidae). Reichenbachia, Staatliches Museum für Tierkunde Dresden, 25(28): 137-147.

Singh, D. \& SAINI, M. S., 1995. New Sawflies of the Genus Tenthredo Linnaeus (Hymenoptera, Symphyta, Tenthredinidae) from India. Annals of Entomology, 13(1): 9-13.

Togashi, I., 1987. Indian sawflies of the Genus Tenthredo (Hymenoptera, Symphyta) Collected by the Expedition of Zoologiske Museum, Copenhagen. Kontyu, 55(1): 51-58.
VASU, V. \& SAINI, M. S., 1999. Three new species of the genus Tenthredo Linnaeus from India (Hymenoptera: Tenthredinidae). Polskie Pismo entomologiczne, 68: 143-150.

WeI, M. \& NiE, H., 1998a. Five new species of Tenthredo of Funiushan (Hymenoptera: Tenthredinidae). Insect Fauna of Henan Province, 2: 170-175.

WeI, M. \& NIE, 1998b. Sixteen new species of Tenthredo of Funiushan (Hymenoptera: Tenthredinidae). Insect Fauna of Henan Province, 2: 188-200.
Recibido, 7-VII-2004

Aceptado, 10-XI-2004

Publicado, 31-XII-2004 